\title{
The Blom-Singer tracheostoma valve as a valuable addition in the rehabilitation of the laryngectomized patient
}

Received: 15 May 1995 / Accepted: 22 June 1995

\begin{abstract}
Prosthesis-assisted tracheo-esophageal speech has proven its value in post-laryngectomy voice rehabilitation, although manual occlusion of the tracheostoma during speech is necessary. In contrast a tracheostoma valve enables hands-free speech. We have now had experience with 30 patients using the Blom-Singer tracheostoma valve for more than 6 months and have found that most patients prefer prosthesis-assisted speech with the tracheostoma valve. Measurement of several speech parameters with digital and valve occlusion of the tracheostoma did not show any significant differences between the two speaking conditions. Problems included maintenance of an airtight seal, outward forcing of the valve diaphragm during forced expiration and subjective increased airflow resistance.
\end{abstract}

Key words Laryngectomy · Voice rehabilitation . Tracheostoma valve $\cdot$ Voice prosthesis

\section{Introduction}

Since Blom and Singer [3] introduced voice prosthesis-assisted tracheo-esophageal speech in 1979, this method for post-laryngectomy voice rehabilitation has proven to be

Adapted from a presentation at the 5th International Congress on Surgical and Prosthetic Voice Restoration after Total Laryngectomy. Grado, Italy, 11 September 1993

F. J. A. van den Hoogen (区) M. J. Oudes - J. J. Manni ${ }^{1}$ Department of ORL, Head and Neck Surgery,

University Hospital Nijmegen, P.O. Box 9101,

6500 HB Nijmegen, The Netherlands

C. Meeuwis - P. Janssen

Department of ORL, Head and Neck Surgery,

Daniel den Hoed Kliniek, Rotterdam, The Netherlands

Present address:

${ }^{1}$ Department of ORL, Head and Neck Surgery,

University Hospital Maastricht, Maastricht, The Netherlands superior to esophageal speech. At University Hospital Nijmegen speech rehabilitation was successful in $80 \%$ of our laryngectomized patients [9]. With the introduction of low-pressure voice prostheses $[6,10,13,14]$ and myotomy of the cricopharyngeal and lower pharyngeal constrictor muscle these results have even further improved $[8,12]$. However, intermittent manual occlusion of the tracheostoma is necessary to create a tracheo-esophageal airflow during speech. This is a non-hygienic, inconvenient procedure for which some dexterity is needed. Of course, it ties hands and draws attention to the laryngectomized status. The stoma size in relation to the size of the fingertip is also of importance.

In 1982 the tracheostoma valve for hands-free alaryngeal prosthetic speech was introduced by Blom et al. [4]. The device consists of a circular housing which is attached to the skin with non-irritating adhesive discs. The valve assembly, supporting the valve diaphragm, can be inserted and removed leaving the housing attached to the skin. In the first-generation device the valve diaphragm was available in four thicknesses that defined the pressure needed to close the valve. The newly developed device has an adjustable valve. The valve sensitivity can be adjusted by rotating the face plate (Fig. 1). It can also be provided with a heat and moisture exchanger (Figs. 2, 3). Since the Blom-Singer valve has become more popular in The Netherlands, we assessed its value in the present study by evaluating the combined experience of University Hospital Nijmegen and the Daniel den Hoed Clinic, Rotterdam, The Netherlands.

\section{Materials and methods}

Thirty laryngectomized patients were selected between June 1992 and May 1993 and provided with a Blom-Singer tracheostoma valve. Selection criteria consisted of existing stoma-occlusion problems because of decreased manual dexterity (e.g. arthritis) or stoma size and/or frequent bimanual activities in combination with speech.

The patients included 24 men and 6 women, with an average age of 59 years (ranging 40-73 years). Twenty-nine patients were using indwelling voice prostheses (low-pressure Groningen voice 
Fig. 1 By rotating the face plate of the tracheostoma valve the diaphragm can be partially closed to adjust the valve's sensitivity
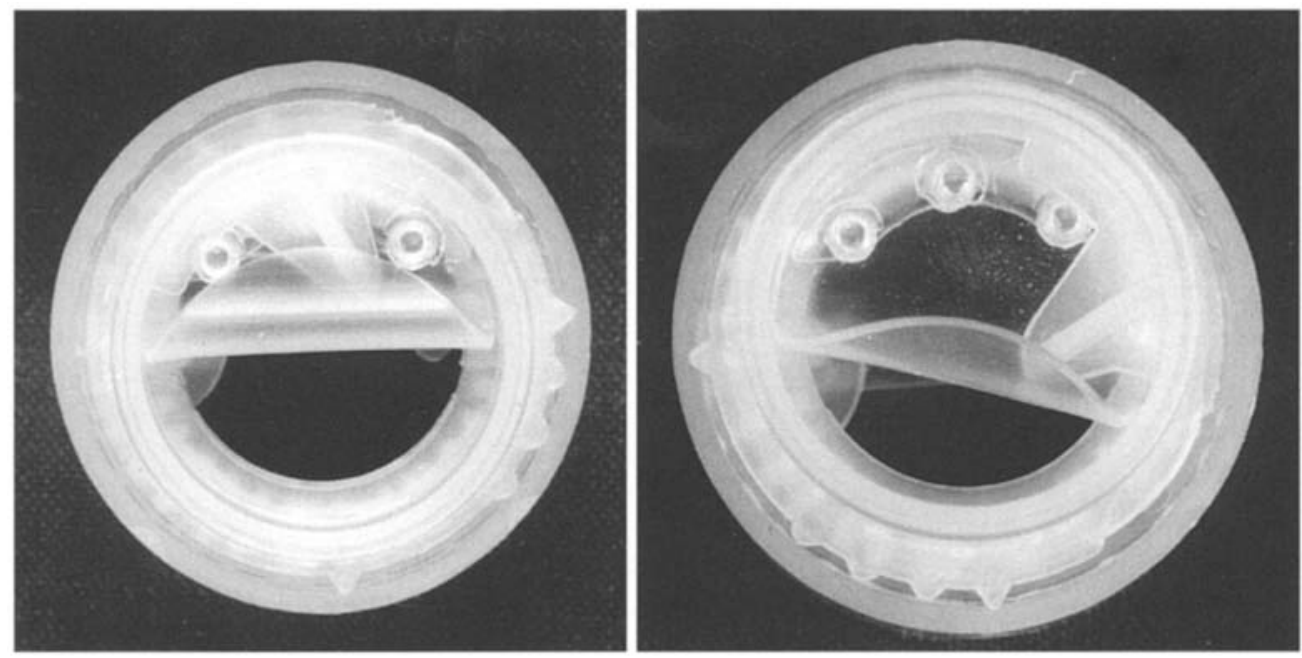

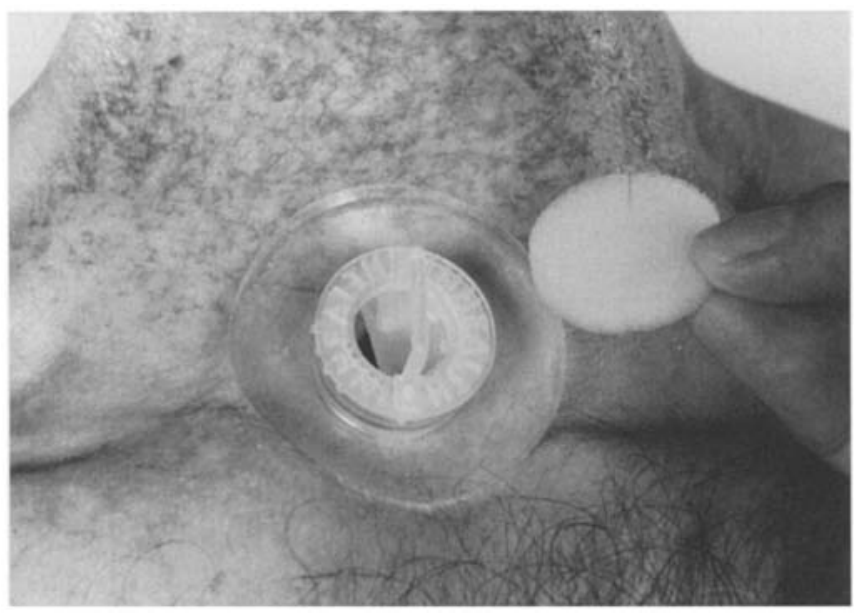

Fig. 2 The Blom-Singer adjustable tracheostoma valve with a foam filter

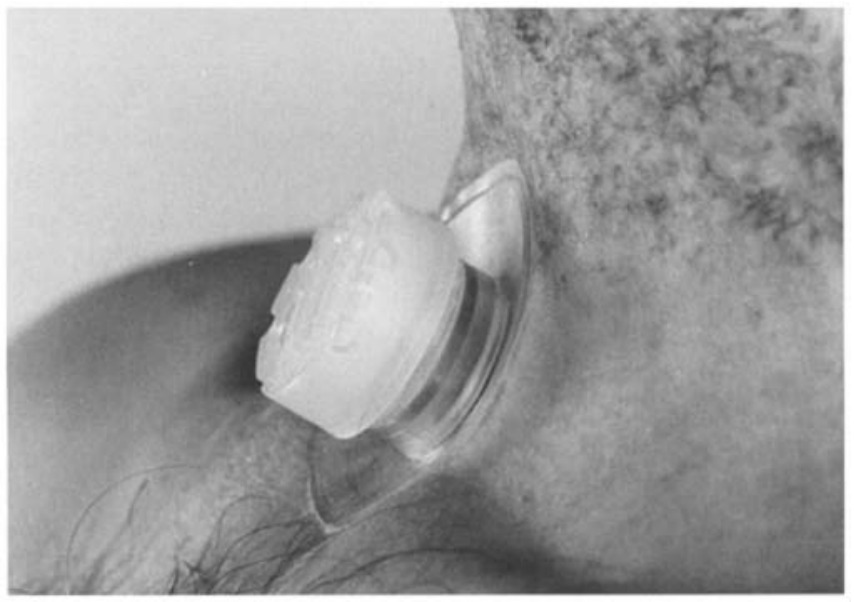

Fig. 3 Lateral view of the adjustable tracheostoma valve in combination with the heat and moisture exchanger, which consists of a removable retaining cap and a replaceable foam filter

prosthesis [14], Provox voice prosthesis [6], Nijdam voice prosthesis [10]). One of them had a well-functioning Staffieri shunt. All were tracheo-esophageal speakers for 3 years on average (range 6 months to 11 years).
The tracheostoma valve was used by the study group for an average period of 6 months, ranging from 3 to 14 months. One patient was excluded because excessive leakage of air underneath the valve housing and skin problems due to erythema, pruritis and a vesicular tash limited his ability to participate.

All Nijmegen patients were asked to return for evaluation of the tracheo-esophageal voice with and without the tracheostoma valve. Recordings were made of 13 patients. All patients in Nijmegen and Rotterdam were also evaluated by questionnaire.

\section{Results}

Manual tracheostoma occlusion was reported to be troublesome by half of the patients. If questioned about their speech rehabilitation approximately $60 \%$ said that esophageal voice alone was unacceptable while $90 \%$ were satisfied with the results attained with the prosthesis-assisted tracheo-esophageal speech. Combination of a valve with the prosthesis improved speech even further. Most patients $(79 \%)$ preferred to speak with the prosthesis, with or without using the valve.

Some patients $(31 \%)$ wore the tracheostoma valve all day but the majority chose specific activities such as visits $(34 \%)$, work $(17 \%)$ or leisure time activities $(14 \%)$.

Tracheostoma valve application was found to be easy and required approximately $10 \mathrm{~min}$. Most patients did not need any assistance with placement. The valve stayed in place for an average period of $7 \mathrm{~h}$, although there was a large interindividual variation (from 1 to $48 \mathrm{~h}$ ). Removal with white spirit or alcohol was no problem. Skin problems were usually mild and mainly consisted of local erythema or pruritis and occurred in $24 \%$ of the patients.

Maintenance of an airtight seal was one of the major problems found in patients and was associated with the anatomy of the jugular fossa, the stemoclavicular joints and/or the sternocleidomastoid muscles. Excessive intratracheal pressure during speech and copious mucus discharge were other significant factors. Outward forcing of the diaphragm, mainly while coughing $(93 \%)$ or with loud speech $(38 \%)$, was a frequently mentioned problem. For $38 \%$ of the patients physical activity was impossible while wearing the tracheostoma valve because of in- 
Table 1 Criteria used for evaluation of tracheo-esophageal speech (adapted from Mahieu [7])

Table 2 Percentages of patients $(n=13)$ judged to be good, moderate or poor tracheo-esophageal speakers for speech parameters under two different occlusion speaking conditions

\begin{tabular}{|c|c|c|c|}
\hline \multirow[t]{2}{*}{ Parameter } & \multicolumn{3}{|l|}{ Speech quality } \\
\hline & Good & Moderate & Poor \\
\hline Availability & $\begin{array}{l}\text { Always immediately } \\
\text { on request; voice } \\
\text { onset delay }<5 \mathrm{~s}\end{array}$ & $\begin{array}{l}\text { Occasionally voice onset } \\
\text { delay }>5 \mathrm{~s} \text { following } \\
\text { request }\end{array}$ & Not available \\
\hline Fluency & $\begin{array}{l}\geq 19 \\
\text { syllables per } \\
\text { air intake }\end{array}$ & $\begin{array}{l}10-18 \\
\text { syllables per } \\
\text { air intake }\end{array}$ & $\begin{array}{l}\leq 9 \\
\text { syllables per } \\
\text { air intake }\end{array}$ \\
\hline Voice modulation & $\begin{array}{l}\text { Adequate } \\
\text { pitch variation }\end{array}$ & $\begin{array}{l}\text { Little } \\
\text { pitch variation }\end{array}$ & Monotonous \\
\hline Speech rate & $\begin{array}{l}\geq 200 \\
\text { syllables/min }\end{array}$ & $\begin{array}{l}150-200 \\
\text { syllables/min }\end{array}$ & $\begin{array}{l}\leq 150 \\
\text { syllables/min }\end{array}$ \\
\hline $\begin{array}{l}\text { Maximum phonation } \\
\text { time }\end{array}$ & $\geq 10 \mathrm{~s}$ & $4-9 \mathrm{~s}$ & $\leq 3 \mathrm{~s}$ \\
\hline Dynamic range & $\geq 25 \mathrm{~dB}$ & $16-24 \mathrm{~dB}$ & $\leq 15 \mathrm{~dB}$ \\
\hline
\end{tabular}

\begin{tabular}{|c|c|c|c|c|c|c|}
\hline \multirow[t]{3}{*}{ Parameter } & \multicolumn{6}{|c|}{ Speech quality } \\
\hline & \multicolumn{2}{|c|}{$\begin{array}{l}\text { Good } \\
\text { occlusion }\end{array}$} & \multicolumn{2}{|c|}{$\begin{array}{l}\text { Moderate } \\
\text { occlusion }\end{array}$} & \multicolumn{2}{|c|}{$\begin{array}{l}\text { Poor } \\
\text { occlusion }\end{array}$} \\
\hline & Valve & Digital & Valve & Digital & Valve & Digital \\
\hline Availability & $92 \%$ & $92 \%$ & $8 \%$ & $8 \%$ & - & - \\
\hline Fluency & $92 \%$ & $85 \%$ & - & - & $8 \%$ & $15 \%$ \\
\hline Voice modulation & $77 \%$ & $77 \%$ & $8 \%$ & $15 \%$ & $15 \%$ & $8 \%$ \\
\hline Speech rate & $85 \%$ & $85 \%$ & $8 \%$ & $8 \%$ & $8 \%$ & $8 \%$ \\
\hline Maximum phonation time & $54 \%$ & $46 \%$ & $31 \%$ & $38 \%$ & $15 \%$ & $15 \%$ \\
\hline Dynamic range & $31 \%$ & $46 \%$ & $46 \%$ & $38 \%$ & $23 \%$ & $15 \%$ \\
\hline
\end{tabular}

creased airway resistance. Fifty percent experienced feelings of an obstructed airway. One third of the patients stated that usage of the valve during upper respiratory infections could be problematic. Some resolution was had with the recently introduced second-generation tracheostoma valve containing an adjustable closing-pressure mechanism. This new device could also be combined with a heat and moisture exchanger to reduce mucus production [2].

Breathing noises and the click when the valve closes were usually not a problem for most of the patients although some found it annoying (17\%). Seventy-eight percent said the effort required to speak was increased with the valve. The quality of speech was believed to be different by $66 \%$. Although there was no significant difference, $28 \%$ noticed a more relaxed voice and $21 \%$ a clearer voice. There was no apparent effect on the length of sentences or loudness of speech.

Criteria used for evaluation of tracheo-esophageal speech are shown in Table 1 [7]. Of the 13 patients from the Nijmegen ENT Department who had recordings made of speech with and without a tracheostoma valve, measurement of speech parameters with or without the valve did not show any significant differences (Table 2).

The tracheostoma valve was appreciated by most of the patients as a hands-free, less conspicuous, more hygienic and more comfortable way to speak in combination with various bimanual activities. One patient suffered from arthritis of his fingers and prosthetic speech became possible only with the use of the valve. Overall, $83 \%$ of the patients stated that they felt less handicapped with use of the tracheostoma valve.

\section{Discussion}

Even though loss of voice can be a devastating side effect of total laryngectomy, a majority of patients are able to produce some degree of esophageal voice. Since the introduction of the voice prosthesis, post-laryngectomy voice production has further improved rehabilitation options. However, manual occlusion of the tracheostoma can be uncomfortable and unhygienic and attracts the eye to the laryngectomized status. Digital pressure on the tracheostoma soft tissue can also possibly increase resistance to airflow through the pharyngo-esophageal (PE) segment. As hypertonicity at the $\mathrm{PE}$ segment is a frequent cause of failure in acquiring esophageal voice [12] this can be considered as an undesirable side effect. Use of the tracheostoma valve seems to solve some of the aforementioned problems.

Evaluation of tracheo-esophageal speech in our patients with and without the tracheostoma valve, according to the criteria shown in Table 1, did not show any significant differences for the speech parameters studied. This confirms the results found by Pauloski et al. [11]. 
Unfavorable peristomal anatomy due to prominent sternocleidomastoid muscles or a deep tracheostoma can cause problems with placement of the tracheostoma valve. To overcome this problem, Barton et al. [1] modified the Helsper button to provide for attachment of a tracheostoma valve. Since the majority of patients do not need a stomal button, we currently do not think that the risk of stoma dilatation, granulation tissue formation or bleeding is worth the potential benefit. The customized valve housing described by Cantu et al. [5] has yet to prove its usefulness.

We would stress from our experience that overproduction of mucus, excessive coughing or a high speaking pressure can be additional unfavorable conditions for use of a tracheostoma valve. These problems remain to be resolved in certain patients. Further development is required in the method of application of the valve, airway resistance and maintenance of an airtight seal. Outward forcing of the valve with loud speech is possibly resolved with introduction of the second-generation Blom-Singer adjustable tracheostoma valve, although coughing can still be a problem. By using a heat and moisture exchanger with the adjustable valve, airway irritation and mucus production can also be reduced significantly. Despite the limitations cited in our study, our findings show that the tracheostoma valve is indeed a valuable addition in voice rehabilitation of the laryngectomized patient.

Acknowledgement The authors wish to thank Mr. Eric Blom for reviewing the manuscript and making helpful comments.

\section{References}

1. Barton D, DeSanto L, Pearson BW, Keith R (1988) An endostomal tracheostomy tube for leakproof retention of the BlomSinger stomal valve. Arch Otolaryngol Head Neck Surg 99: $38-41$
2. Blom ED (1993) Laboratory and clinical investigation of postlaryngectomy airway humidification and filtration. Book of abstracts, 1st EGFL Conference and 5th International Congress on Surgical and Prosthetic Voice Restoration After Total Laryngectomy, 10-12 September, Grado, Italy

3. Blom ED, Singer MI (1979) Surgical-prosthetic approaches for postlaryngectomy voice restoration. In: Keith RL, Darley FL (eds) Laryngectomee rehabilitation. College Hill Press, Houston, pp 251-276

4. Blom ED, Singer MI, Hamaker RC (1982) Tracheostoma valve for postlaryngectomy voice rehabilitation. Ann Otol Rhinol Laryngol 91:576-578

5. Cantu E, Shagets FW, Fifer RC, Andres CJ, Newton AD (1986) Customized valve housing. Laryngoscope 96:11591163

6. Hilgers FJM, Schouwenburg PF (1990) A new low-resistance, self-retaining prosthesis (Provox) for voice rehabilitation after total laryngectomy. Laryngoscope 100:1202-1207

7. Mahieu HF (1988) Voice and speech rehabilitation following laryngectomy. PhD thesis, Groningen University, The Netherlands

8. Mahieu HF, Annyas AA, Schutte HK, Jagt EJ van der (1987) Pharyngo-esophageal myotomy for vocal rehabilitation of laryngectomees. Laryngoscope 97:451-457

9. Manni JJ, Broek P van den (1990) Surgical and prosthesis-related complications using the Groningen button voice prosthesis. Clin Otolaryngol 15:515-523

10. Nijdam HF, Manni JJ, Nicolasen M (1990) A new valveless low-pressure voice prosthesis. Clin Otolaryngol 15:561

11. Pauloski BR, Fisher HB, Kempster GB, Blom ED (1989) Statistical differentiation of tracheoesophageal speech produced under four prosthetic/occlusion speaking condi-tions. J Speech Hear Res 32:591-599

12. Singer MI, Blom ED (1981) Selective myotomy for voice restoration after total laryngectomy. Arch Otolaryngol Head Neck Surg 107:670-673

13. Smith BE (1986) Aerodynamic characteristics of Blom-Singer low-pressure voice prostheses. Arch Otolaryngol Head Neck Surg 112:50--52

14. Zijlstra RJ, Mahieu HF, Lith-Bijl JT van, Schutte HK (1991) Aerodynamic properties of the low-resistance Groningen button. Arch Otolaryngol Head Neck Surg 117:657-661 